\title{
Decolonialidade e inglês como língua franca: diálogos com professores brasileiros
}

\author{
Decoloniality and English as a lingua franca: dialogues \\ with Brazilian teachers
}

\author{
Camila Haus* \\ Mariana Lyra Varela de Albuquerque ${ }^{* *}$
}

RESUMO: As relações interculturais que caracterizam nossa realidade globalizada são permeadas pela colonialidade. No contexto do ensino de inglês, enxergamos o deslocamento de um paradigma de inglês como língua estrangeira para perspectivas mais críticas (como de inglês como língua franca (ILF) e translinguagem) como possível caminho para a decolonialidade. Assim, neste trabalho, entrevistamos professores a respeito de seus planejamentos, recursos e crenças sobre os investimentos dos alunos no aprendizado. Ao voltarmo-nos para esses discursos, buscamos refletir sobre a possível presença de elementos que indiquem uma perspectiva de ILF e translinguagem, considerando, por um lado, uma desobediência epistêmica (MIGNOLO, 2008) e, por outro, uma perpetuação do imperialismo linguístico característico da colonialidade. Por fim, destacamos a importância de uma formação inicial/continuada de professores que contribua para a autorreflexão e o questionamento.

PALAVRAS-CHAVE: Inglês como língua franca; práticas translíngues; decolonialidade.

ABSTRACT: The intercultural relations which characterize our globalized reality are permeated by coloniality. In the context of English teaching, we see the shift from an EFL paradigm to more critical perspectives (such as English as a lingua franca (ELF) and translanguaging) as a possible path towards decoloniality. Thus, in this paper we interviewed teachers about their plannings, resources and beliefs regarding students' investments in learning. As we turn to these discourses, we aim to reflect upon the possible presence of elements which indicate an ELF and translingual perspective, considering, on the one hand, an epistemic disobedience (MIGNOLO, 2008), and, on the other, a perpetuation of the linguistic imperialism typical of coloniality. Finally, we highlight the importance of an initial/continued teacher education process that contributes to self-reflection and questioning.

KEYWORDS: English as a lingua franca; translingual practices; decoloniality.

\footnotetext{
* Doutoranda em Estudos Linguísticos na Universidade Federal do Paraná (UFPR), bolsista CAPES, camila.haus@gmail.com, ORCID https://orcid.org/oooo-0003-4522-8992.

${ }^{* *}$ Mestranda em Estudos Linguísticos na Universidade Federal do Paraná (UFPR), bolsista CAPES, lyraa.mariana@gmail.com, ORCID https://orcid.org/oooo-0002-2063-9026.
} 


\section{Introdução}

Muito se tem dito sobre a realidade interconectada em que vivemos hoje, considerando os grandes fluxos de pessoas, bens, conhecimentos e culturas que a tecnologia, a internet e os rápidos meios de transporte possibilitam. O termo globalização tem sido amplamente utilizado na tentativa de dar conta dessa realidade, caracterizada pela fluidez e pelo contato. Considerando a ideia de glocalização de Menezes de Souza (2019), reconhecemos que os processos de contato entre diversos globais e locais ocorrem em diferentes graus, com momentos de convergência e divergência, de interconectividade e resistência, de interação e emancipação. Em todo contato entre global e local, há recontextualização e ressignificação tanto de elementos tidos como globais (sabendo que estes sempre serão o local de algum grupo) quanto locais. É importante destacar, como aponta Mufwene (2010, p. 31), que os volumes e direções desses tráfegos não são necessariamente simétricos, uma vez que os sujeitos e entidades envolvidas não possuem o mesmo poder econômico, social ou político: "são os mais poderosos que controlam quais populações e mercadorias (incluindo línguas) são transportadas livremente e em que direções” (tradução nossa55). Acreditamos que essa existência de um determinado grupo que determina o que é ou não considerado global ocorre devido à colonialidade (MIGNOLO, 2008; 2014; MALDONADO-TORRES, 2007; SOUSA SANTOS, 2007; 2010; 2011; QUIJANO, 2000). São os processos de colonização epistemológica, linguística e cultural que ditam o que é considerado global, assim como geram apagamentos de determinados locais.

Uma vez que olhamos para a realidade contemporânea reconhecendo a colonialidade que permeia os processos de globalização, percebemos a necessidade de observar como tais processos têm acontecido em nosso contexto de professores de inglês. No que concerne ao ensino dessa língua em escolas de

55 "It is the more powerful who control which populations and commodities (including languages) are transported more freely, and in which directions". 
idiomas e ensino regular no Brasil (ou mesmo em outros países, cuja realidade acessamos por meio de textos teóricos), construtos coloniais como a orientação monolíngue e a tradição do ensino de inglês como língua estrangeira (ILE) parecem ainda prevalecer atualmente, além de uma percepção de superioridade de livros didáticos, métodos e tecnologias produzidos no norte global. $\mathrm{O}$ desenvolvimento de currículos e avaliações ainda é orientado por uma perspectiva de língua como sistema comum e compartilhado, composto por uma norma, a qual pertence, que é regida por um construto idealizado de falante nativo (CANAGARAJAH, 2013; JENKINS, 2015), normalmente vinculado a países do norte global, como Estados Unidos e Inglaterra. Cabe ressaltar que há outros fatores, como raça, classe e gênero, que também fazem parte dessa idealização. Tal construção gera em professores e aprendizes de inglês um sentimento de ineficiência e de falha constante, por buscarem incessantemente esse modelo.

Em contrapartida, existem muitas pesquisas na área da Linguística Aplicada (LA), como as perspectivas de inglês como língua franca (ILF) (FRIEDRICH; MATSUDA, 2010; JENKINS, 2015; JORDÃO; MARQUES, 2018) e de práticas translíngues (CANAGARAJAH, 2013; PENNYCOOK, 2008; GARCÍA; WEI, 2014), que parecem se distanciar de construtos coloniais tais como o conceito de línguas como entidades separadas ou de determinados grupos de falantes como modelos de superioridade no uso do idioma. Nessas perspectivas, identificamos que pensamentos dominantes, que nutrem a lógica colonial/moderna, são desafiados. Como exemplo, ressaltamos como preocupações de ILF e das práticas translíngues o tensionamento da centralidade daqueles que sempre estiveram no poder, o questionamento sobre o que é considerado erro, assim como o direcionamento do ensino/aprendizagem às necessidades locais. Nesse sentido, percebemos uma atitude de desobediência epistêmica (MIGNOLO, 2008), já que, ao contrariar essa lógica dominante, há uma tentativa de valorização dos saberes de outros sujeitos.

Entretanto, cabe ressaltar que nem tudo relacionado a ILF e às práticas translíngues pode ser considerado decolonial, uma vez que essas teorias podem 
ser entendidas de diferentes formas, inclusive sendo incorporadas por uma lógica capitalista neoliberal. Por exemplo, acreditamos que existem certas pesquisas feitas na área de ILF que acabam neutralizando questões de poder imbricadas no uso da língua inglesa, ao focarem na negociação dos recursos linguísticos e semióticos e negligenciarem relações desiguais e/ou identidades de raça, gênero e classe dos falantes. Assim, em vez de desafiar estruturas a fim de promover a igualdade, tais concepções reforçam assimetrias e exclusões. Reconhecemos, portanto, que as conclusões tiradas ao longo deste artigo são baseadas nas nossas percepções a respeito de um entendimento de ILF e práticas translíngues em uma realidade particular e situada, que parecem indicar certa transformação.

Tendo em vista esse cenário e considerando nossa identidade de professoras de língua inglesa no Brasil, o presente trabalho pretende refletir sobre discursos de professores de inglês do Centro de Línguas e Interculturalidade (Celin) da Universidade Federal do Paraná (UFPR) a respeito de suas práticas e crenças em sala de aula. Em nossa análise, debateremos uma possível presença de elementos voltados a uma perspectiva translíngue de ILF, considerando, por um lado, uma desobediência epistêmica e, por outro, uma propagação e perpetuação do imperialismo linguístico característico da colonialidade.

A fim de alcançar tal objetivo, entrevistamos quatro professores de inglês da instituição antes referida sobre seus planejamentos de ensino, suas escolhas de materiais e recursos, bem como suas crenças sobre os investimentos dos alunos no aprendizado da língua. Neste artigo, iniciamos com um breve apanhado teórico a respeito de colonialidade e uma perspectiva translíngue de ILF. Em seguida, trazemos a metodologia e as análises dos discursos dos professores, finalizando com algumas considerações.

\section{Colonialidade}

Muitos pesquisadores afinados com a temática da colonialidade têm debatido os efeitos de tal fenômeno na produção de conhecimento, na 
organização de trabalho, nas relações intersubjetivas, na própria visão de povos, no senso comum, entre outros. Os efeitos da colonialidade ultrapassam os limites do período da colonização, pois permanecem até hoje no pensamento e nas práticas de muitos sujeitos, invisibilizando e marginalizando grupos sociais e saberes considerados - no sistema-mundo europeu/euro-norteamericano/capitalista/patriarcal/moderno/colonial （GROSFOGUEL， 2013) ignorantes, primitivos, inferiores, locais e improdutivos. Segundo MaldonadoTorres (2007), o colonialismo, enquanto experiência em que a soberania de um povo estava nas mãos de outro povo ou nação, pode ter acabado, mas o que se originou com a conquista, dominação e colonização dos povos e dos territórios, isto é, a colonialidade, continua existindo e condicionando muitas pessoas, pensamentos e ações. Em outras palavras, "apesar de o colonialismo preceder a colonialidade, a colonialidade sobrevive ao colonialismo" (MALDONADOTORRES, 2007, p. 131, tradução nossa56).

De acordo com o sociólogo português Boaventura de Sousa Santos (2007), a aventura colonial europeia foi um projeto de colonialismo e capitalismo global que gerou uma divisão abissal entre aquilo que hoje chamamos de norte global e sul global57. Para o autor, o norte e o sul global são separados por linhas imaginárias que dividem as realidades no universo deste lado da linha e o universo do outro lado da linha, o que transforma o pensamento moderno ocidental em um pensamento abissal. O traço principal desse pensamento é a radicalização de distinções, pois tudo aquilo que é produzido do outro lado da linha é invisibilizado, inexistente e radicalmente excluído.

A distinção entre colonialismo e colonialidade se apresenta como premissa para o conjunto de pensadores que integram ou se relacionam ao grupo de pesquisa Modernidade/Colonialidade. Esses pesquisadores enfatizam a

\footnotetext{
${ }_{56}$ "Así, pues, aunque el colonialismo precede a la colonialidad, la colonialidad sobrevive al colonialismo".

57 Para Sousa Santos (2011, p. 28-29), o norte global são os "países centrais ou desenvolvidos, quer se encontrem no Norte geográfico, quer no Sul geográfico, como sucede com a Austrália e a Nova Zelândia. Em contraposição, o Sul é o conjunto de países periféricos e semiperiféricos”. Assim, entende-se que não se trata do posicionamento geográfico, mas, sim, geopolítico mundial. Entretanto, é muito importante enfatizar que, mesmo no norte global, o sul está presente, e vicee-versa, pois há sempre pessoas e pensamentos marginalizados, excluídos e destituídos de valor.
} 
inseparabilidade da modernidade/colonialidade e problematizam a narrativa dominante do norte global, ou seja, defendem uma perspectiva decolonial. Na decolonialidade, as histórias consideradas únicas e globais são questionadas, já que se reconhece que "no mundo há muito para aprender com aqueles outros que a modernidade tornou invisíveis (MALDONADO-TORRES, 2008, p. 108-109)”. Ou seja, há uma ênfase na construção de um mundo no qual coexistam diferentes saberes, seres, tempos, espiritualidades etc.

De acordo com a perspectiva da decolonialidade, para transformar a realidade colonial, é necessário que sejamos epistemologicamente desobedientes (MIGNOLO, 2008), isto é, que questionemos e desobedeçamos padrões hegemônicos e eurocêntricos de produção de conhecimento, a fim de reconhecer os saberes e o modo de vida daqueles que foram radicalmente silenciados, marginalizados e invisibilizados pela colonialidade. Visando a pluralidade, Sousa Santos (2007) nos apresenta o conceito de ecologia de saberes, que enfatiza a importância da coexistência de diferentes conhecimentos e de suas interações sustentáveis e dinâmicas. Com isso, não se trata de abdicar ou eliminar os conhecimentos oriundos do norte global, mas de descentralizar a posição do norte de único detentor de conhecimento e colocá-lo no mesmo patamar de importância que o sul global.

\section{A língua inglesa e a colonialidade}

No campo da LA, autores como Pennycook (1998), Kumaravadivelu (2009), bem como os brasileiros Moita Lopes (2006), Siqueira (2018) e Jordão (2010) apontam os efeitos violentos de construtos da colonialidade para o nosso pensar, fazer e dizer. Para Siqueira (2018), muitos construtos e visões coloniais têm sustentado a indústria relacionada ao ensino de línguas e necessitam ser desconstruídos e repensados. Segundo o autor, as línguas sempre estiveram ligadas aos impérios e às suas aventuras coloniais. Como exemplo, Siqueira (2018) - tendo como referência Kumuravadivelu (2009) - comenta acerca do 
trajeto da língua inglesa, que possui traços coloniais baseados em quatro dimensões inter-relacionadas: acadêmica, linguística, cultural e econômica. Tais dimensões mostram como o conhecimento ocidental se sobrepôs aos conhecimentos e línguas locais, gerando riqueza para países hegemônicos de língua inglesa, uma vez que o ensino dessa língua se tornou um grande negócio.

Em concordância com a discussão apresentada por Siqueira (2018) e Kumaravadivelu (2009), Jordão (2004) afirma que a língua inglesa, afinada com uma lógica capitalista neoliberal, tornou-se uma commodity no mundo. Segundo a autora, essa língua se transformou em um objeto passível de compra e venda, colocada como produto de consumo. Assim, muitos professores, cursos de idiomas e alunos creem e vendem a ideia de que o domínio do inglês lhes garantirá um sucesso econômico e social, pois, com isso, alcançarão melhores posições na sociedade.

Essa commodity gera riqueza e empregos para os países hegemônicos de língua inglesa ao manter desigualdades, subalternizando e excluindo qualquer realidade distinta. A insistência na separação entre nativos e não nativos, a constante reprodução de modelos vindos do norte global, a ideia de que a língua inglesa carrega uma racionalidade e intelectualidade superior a outras línguas fenômenos que os autores citados no início desta seção e muitos outros na área de LA vêm observando - são exemplos de colonialidade e manutenção do poder oriundos daquele lado da linha abissal. Tais pensamentos informam as identidades e práticas de estudantes e docentes, influenciando violentamente as maneiras como esses sujeitos se veem e são vistos na sociedade.

Cabe ressaltar que tamanha é a dominação e a invasão do imaginário dos sujeitos subalternizados que, por vezes, a perspectiva cognitiva colonial torna-se também a visão daquele que foi marginalizado. Mignolo (2014) afirma que, para pensar o mundo de maneira decolonial, temos que refletir, primeiramente, acerca da nossa própria condição. Segundo o autor,

[p]ara derrubar a geografia do raciocínio moderno, o método e o tópico, a observação e a descrição, o sujeito cognoscente e o objeto a conhecer, etc., é fundamental tomar consciência de que não se pode observar de 
fora o padrão colonial de poder: todos estamos inseridos nele. (MIGNOLO, 2014, p. 63, tradução nossa ${ }^{8}$ )

Portanto, não é possível pensar a matriz de poder e a diferença colonial sem que nos entendamos como parte da colonialidade.

\section{Inglês como língua franca e a decolonialidade}

Diante desse cenário de predominância de construtos coloniais no ensino de inglês, deparamo-nos com o seguinte questionamento: professores estariam condicionados a seguir os pressupostos da colonialidade ou haveria espaço para uma desobediência epistêmica? Se retomarmos a ideia de glocalização citada na introdução deste artigo, não existe uma simples assimilação daquilo que se considera global, mas o contato com os diversos locais se caracteriza também pela resistência, ressignificação e divergência. Jordão (2010, p. 431) afirma que tal resistência é "consequência do posicionamento do sujeito num local de fronteira, na margem do processo, num terceiro espaço que não é nem o espaço ocupado pelo colonizador/opressor nem pelo colonizado/oprimido: é um espaço híbrido onde narrativas totalizadoras são desafiadas" (grifos da autora). Ou seja, acreditamos que há, sim, espaço para agência tanto dos alunos quanto dos profissionais envolvidos no processo de ensino de inglês. Essa agência pode ser observada em atos de desobediência epistêmica.

$\mathrm{Na}$ área da LA, percebemos diversos movimentos em direção a perspectivas menos coloniais, que desafiam conceitos que essencializam ou atribuem território/posse à língua. Neste artigo, tomamos principalmente o campo de ILF como um exemplo desses movimentos. Reconhecemos que esse campo é largamente utilizado com pressupostos, conceitos e objetivos diferentes, porém, nos referimos a ILF, com base em determinados autores (FRIEDRICH;

58 "Para dar un vuelco a la geografía del razonamiento moderno, al método y al tema, a la observación y a la descripción, al sujeto cognoscente y objeto a conocer, etc., es fundamental tomar conciencia que el patrón colonial de poder no se puede observar desde afuera: todos estamos insertos en él”. 
MATSUDA, 2010; CANAGARAJAH， 2007; JENKINS， 2015; JORDÃO; MARQUES, 2018; SIQUEIRA, 2018), como um contexto de uso de língua inglesa em situações de comunicação entre falantes de diversas origens (distintas ou não entre si), que envolvem recursos linguísticos e semióticos usados em um processo social de negociação situada e contínua de significados.

Nesse conceito, trazemos algumas aproximações com a perspectiva translíngue (CANAGARAJAH, 2007; 2013; GARCÍA; WEI, 2014), relação já proposta por Pennycook (2008, p. 30.3), a fim de desenvolver ILF como "uma tentativa de dar conta das negociações amorfas, contínuas, momento-a-momento do inglês" (tradução nossa 59 ). Primeiro, observamos a linguagem nessas interações a partir do fato de que as línguas não são entidades separadas. Como apontam Makoni e Pennycook (2007), línguas codificadas como sistemas organizados e pertencentes a locais e/ou pessoas foram inventadas ${ }^{60}$, ou seja, sujeitos possuem repertórios que só são marcados como pertencentes a uma língua ou outra sócio-politicamente (GARCÍA; WEI, 2014). Desse modo, além do que chamamos de inglês, nas situações de ILF, todos os recursos linguísticos (provenientes dos construtos que definimos como línguas) do falante estão presentes. Além disso, reconhecemos que essas interações de ILF envolvem também negociações de recursos semióticos, modos (CANAGARAJAH, 2007; 2013), identidades e culturas ${ }^{61}$. Por fim, linguagem é prática social, pois não existe um produto ou um sistema comum utilizado pelos falantes ou presente em suas mentes, mas um processo sendo constantemente recriado como forma de ação (CANAGARAJAH, 2007; 2013; PENNYCOOK, 2008; GARCÍA; WEI, 2014).

Nessa visão de ILF que se aproxima de práticas translíngues, a negociação nas interações se torna foco na construção de significados. Uma vez que a língua

59 "An attempt to account for the amorphous, ongoing, moment-by-moment negotiation of English".

${ }^{60}$ Apesar de reconhecermos tal invenção das línguas, continuaremos utilizando termos como língua e, principalmente, inglês, pois a materialização e o reconhecimento social desses construtos é real, bem como os efeitos materiais dessa construção (MAKONI; PENNYCOOK, 2007).

${ }^{61}$ De acordo com Garcia e Wei (2014), translinguagem envolve transculturação, ou seja, um processo de surgimento de novas realidades complexas, nas quais histórias, culturas e entendimentos antes apagados se tornam visíveis. 
não é vista como um sistema comum entre os falantes, a inteligibilidade não ocorre por meio de formas compartilhadas, mas, sim, de estratégias utilizadas pelos participantes de uma interação, onde sentidos são negociados e renegociados com base nos objetivos e interesses comunicativos da situação (CANAGARAJAH 2007; 2013; FRIEDRICH; MATSUDA, 2010). Consequentemente, o papel de modelo antes exercido pelo falante nativo ou outra força externa de normatividade é descentralizado. Entretanto, é preciso lembrar que em toda interação existem diferenças identitárias e culturais, assim como relações de poder assimétricas. Em outras palavras, é possível que nem todos os falantes em determinada situação estejam dispostos à negociação, e é nesses casos que a inteligibilidade pode não acontecer.

Considerando a perda do espaço privilegiado do modelo de falante nativo, o empoderamento dos falantes considerados não nativos, cada qual com seus recursos e estratégias de negociação, e o foco na fluidez, na diferença e na translinguagem, essa visão de ILF tira a centralidade dos que sempre estiveram no poder, volta-se para a contingencialidade e localidade e, portanto, caracterizase como uma possível desobediência epistêmica. Alinhamos nossa perspectiva a Siqueira (2018, p. 99) ao compreender tal fenômeno como "[...] profundamente inter(trans)cultural que, por excelência, se materializa em espaços onde deve predominar o desejo de se explorar e aceitar diferenças na comunicação, relativizar valores e posturas", e, dessa forma, "[...] emerge também como um importante espaço de descolonialidade" (SIQUEIRA, 2018, p. 104). A possibilidade de abertura para diferentes sentidos na perspectiva de ILF e translinguagem é apontada por Pennycook (2008, p. 30.5) como uma "[...] ação política, uma forma de confrontar as possíveis ameaças à diversidade" (tradução nossa $^{62}$ ).

Como pesquisadoras, estamos cientes de que, ao adotarmos certos termos e conceitos, temos a obrigação de observá-los criticamente, a fim de repensá-los de forma local. Diniz de Figueiredo e Martinez (2019) chamam atenção para os perigos de transpor conceitos e termos de forma acrítica e deslocada, sem

62 "[...] political action, as a way of confronting the possible threats to diversity". 
observar que algumas teorias - principalmente aquelas vindas do norte global escondem e reforçam desigualdades no que tange à produção de conhecimento.

Ao adotarmos o conceito de ILF e práticas translíngues, portanto, enxergamos um movimento rumo à decolonialidade. Porém, também sabemos que os entendimentos sobre esses conceitos são os mais diversos possíveis, a depender de quem os interpreta. Preocupa-nos, por exemplo, que as ideias relacionadas à perspectiva translíngue de ILF imponham questões distantes da realidade local, bem como enredem-se em uma lógica de mercado que instrumentaliza a língua inglesa, transformando-a em mero bem de consumo. Com isso, em vez de promovermos a igualdade, estaremos incentivando desigualdade e marginalização. Reconhecendo, portanto, tais ressalvas, neste trabalho, focamos nos elementos de ILF e translinguagem presentes nos discursos dos professores, os quais acreditamos estarem próximos de uma atitude que desafia valores e posturas coloniais, na esperança de que tais perspectivas possam ser transformadas em espaços de agência nas salas de aula de inglês no Brasil.

\section{Metodologia}

As conversas analisadas neste trabalho foram realizadas em julho de 2019, no Centro de Línguas e Interculturalidade da Universidade Federal do Paraná (Celin - UFPR). Esse centro atende às comunidades interna e externa da universidade, sendo a maioria do público composta por alunos da graduação e o corpo docente por alunos e ex-alunos de licenciatura em Letras. Reuniões com intuito administrativo e pedagógico são realizadas mensalmente e conduzidas por um coordenador, professor do curso de Letras da UFPR.

Pelo fato de o Celin ser um projeto de extensão da universidade, e por haver um intenso trabalho com a formação inicial e continuada de professores de línguas, imaginamos que discussões relacionadas a ILF e a perspectivas decoloniais poderiam ser familiares a alguns dos profissionais atuantes no centro 
de línguas. Tal expectativa se concretizou nas entrevistas, conforme apresentaremos na seção das análises.

A partir da disponibilidade dos professores, selecionamos quatro sujeitos para responderem a uma entrevista semiestruturada gravada e transcrita (cerca de 20 minutos cada). Aplicamos também um questionário de perfil socioeducacional, cujas informações resumimos no seguinte quadro:

Quadro 1 - Dados de perfil sócio educacional63

\begin{tabular}{|c|c|c|c|c|}
\hline & José & Giovana & Anderson & Aline \\
\hline Idade & 20 anos & 31 anos & 27 anos & 25 anos \\
\hline Formação & $\begin{array}{c}\text { Licenciado em } \\
\text { Letras } \\
\text { Português/Inglês }\end{array}$ & $\begin{array}{c}\text { Bacharel } \\
\text { em Letras } \\
\text { Inglês; } \\
\text { Bacharel } \\
\text { em Biologia }\end{array}$ & $\begin{array}{c}\text { Licenciado em } \\
\text { Letras } \\
\text { Português/Inglês; } \\
\text { Mestre em } \\
\text { Estudos } \\
\text { Linguística }\end{array}$ & $\begin{array}{c}\text { Licenciada em } \\
\text { Letras } \\
\text { Português/Inglês; } \\
\text { Mestra em } \\
\text { Estudos } \\
\text { Literários }\end{array}$ \\
\hline $\begin{array}{c}\text { Tempo de } \\
\text { experiência } \\
\text { como } \\
\text { professor }\end{array}$ & 1 ano & 8 anos & 8 anos & 6 anos \\
\hline $\begin{array}{l}\text { Experiência } \\
\text { de Ensino }\end{array}$ & $\begin{array}{c}\text { Cursos de } \\
\text { idiomas; } \\
\text { Aulas } \\
\text { particulares }\end{array}$ & $\begin{array}{c}\text { Cursos de } \\
\text { idiomas; } \\
\text { Aulas } \\
\text { particulares }\end{array}$ & $\begin{array}{c}\text { Curso de } \\
\text { idiomas; } \\
\text { Aulas } \\
\text { particulares }\end{array}$ & $\begin{array}{c}\text { Curso de } \\
\text { idiomas; } \\
\text { Aulas } \\
\text { particulares; } \\
\text { Escolas } \\
\text { regulares }\end{array}$ \\
\hline
\end{tabular}

Fonte: Elaborado pelas autoras.

${ }^{63}$ Foram utilizados nomes fictícios, dada a necessidade de preservar as identidades dos participantes. 
É possível observar que os professores apresentam pouca variação quanto à faixa etária e às experiências de ensino, mas possuem formações e tempos de experiência diferentes. Quanto à entrevista, as perguntas norteadoras foram:

a) Quais aspectos você considera ao realizar o planejamento das suas aulas?

b) Como você normalmente estrutura as suas aulas?

c) Quais recursos, fora o material didático, você costuma utilizar? E quais são os critérios para as suas escolhas?

d) Na sua experiência como professor do Celin, quais são os principais motivos que levam os seus alunos a estudarem inglês?

e) Para você, qual é o papel do inglês na contemporaneidade? E esse papel afeta de alguma forma as suas práticas de ensino? Como?

f) Dentro de sua trajetória de vida (pessoal, acadêmica, profissional), o que você acredita que influenciou/influencia sua identidade de professor?

Tais perguntas foram desenvolvidas com o objetivo de analisar os discursos dos sujeitos no tocante a seus planejamentos e suas aulas, bem como suas crenças a respeito do investimento dos alunos e de suas identidades como professores de língua inglesa. Entretanto, outros questionamentos também foram inseridos durante a entrevista conforme sentíamos necessidade ou oportunidade junto aos sujeitos da pesquisa.

\section{Análise das entrevistas}

Nesta etapa do artigo, analisaremos algumas das falas dos professores entrevistados, as quais estão constituídas pelo nosso olhar, como pesquisadoras, em relação às teorias lidas e dialogadas, aos dados gerados, bem como ao nosso contexto social, histórico e cultural. Assim, não temos a pretensão de esgotar o tema ou trazer verdade e julgamentos sobre as práticas dos docentes que 
aceitaram participar da nossa pesquisa. Reconhecemos a subjetividade do método de pesquisa adotado e concordamos com a perspectiva de Maher (2010, p. 39) quando afirma que “a objetividade absoluta é um mito”. Dessa forma, acreditamos que a objetividade/racionalidade também é um construto ocidental/colonial.

Tendo isso esclarecido, passamos às nossas escolhas de análise. Optamos por categorizar os dados gerados em dois principais pontos: (1) discursos que reforçam o papel imperialista/colonial da língua inglesa, e (2) discursos que indicam uma desobediência epistêmica. Entendemos que tal categorização não é estanque, e, por vezes, os posicionamentos e exemplos trazidos perpassam as duas categorias ao mesmo tempo. Tal característica dos dados destaca a forma fluída e emaranhada pela qual os professores se relacionam com a língua inglesa. Ao mesmo tempo em que, por vezes, dão continuidade à modernidade/colonialidade, também se colocam como seres agentivos, capazes de transformar realidades, desafiando as relações de poder e questionando o status quo.

\subsection{Papel imperialista/colonial da língua inglesa}

Iniciamos com o ponto número (1), isto é, relacionando-nos com os discursos que reforçam o papel imperialista/colonial da língua inglesa. Notamos que emerge, na fala de algumas docentes, a ideia de que o inglês é uma língua global, associada ao sucesso econômico, laboral e cultural. Assim, dois dos quatro professores entrevistados defendem a ideia de que os alunos devem aprender esse idioma com o intuito de se colocarem no mercado de trabalho, de estarem alinhados aos novos descobrimentos da ciência, da tecnologia e da cultura.

Talvez [o inglês seja importante por] questões econômicas e políticas, né, porque a economia gira em torno dos EUA. [...] eles têm que falar com algum escritório nos EUA ou alguma multinacional que tem relação com os EUA [...]. [...] é a língua eleita, é a língua global, né, então não tem muito como fugir dela. (Giovana) 
Querendo ou não, o inglês no mercado de trabalho não é mais um a mais [...]. [...] inglês é a língua do business, Hollywood, filmes, música. Eu acho que é importante a gente aprender inglês na escola, talvez fazer com que o inglês na escola seja suficiente, porque infelizmente hoje eu vejo que não é o suficiente porque... Não precisa gostar. Eu também não gostava de matemática, mas eu sei me virar em matemática. Eu acho que os alunos têm que pelo menos saber se virar em inglês. (Aline)

Podemos interpretar - pelas falas das duas docentes - que o conhecimento do inglês seria uma espécie de passaporte para o mundo globalizado ocidental, isto é, uma espécie de mal necessário para que acessemos bens materiais e simbólicos. Nele, são depositadas esperanças de melhora financeira, social e cultural, tornando-se uma commodity (JORDÃO, 2004), um produto. Em outras palavras, essa língua pode ser vendida e adquirida como um objeto capaz de fazer com que cidadãos de classes sociais e culturas menos privilegiadas subam na escala social. Com isso, muitas pessoas também associam o inglês com uma falsa ideia de "[...] racionalidade e habilidade intelectual" (NORTON, 2007, p. 9). Assim, aqueles que têm um suposto domínio dessa língua são postos em uma posição de destaque em relação àqueles que dominam outras línguas. Reforça-se, portanto, a diferença colonial entre aqueles que detêm o conhecimento validado pelo Norte e aqueles que não o têm.

Além disso, apesar de Giovana citar as questões políticas e econômicas da língua inglesa, pois a economia gira em torno dos EUA, ela nos leva a interpretar, por meio de sua declaração, que a hegemonia do inglês é natural, uma vez que é a língua eleita, [...] não dá pra fugir dela. Como a entrevistada não tensiona em nossa conversa os fatores que levaram à ascensão da língua inglesa nem a herança colonial/moderna presente nessa naturalidade, não sabemos se suas práticas em sala de aula são questionadoras de tal hegemonia. Consideramos que a falta desse questionamento e, portanto, do desenvolvimento de uma consciência crítica por parte dos alunos, faz com que a língua inglesa continue a ocupar uma posição de superioridade em relação a outras línguas.

Por fim, observamos que esses trechos também reforçam o papel imperialista/colonial da língua inglesa ao localizá-la geográfica e ideologicamente em espaços essencializados do norte global, como EUA, Hollywood etc. Além de 
legitimar o poder desses locais, tal visão de língua está associada à famosa tríade herderiana de língua, comunidade e território (CANAGARAJAH, 2013), paradigma base na concepção moderna de língua e fundamental aos processos de colonização.

No sentido oposto do posicionamento tomado por Giovana e Aline, o professor Anderson reconhece que a língua inglesa não é neutra, mas, sim, política, histórica e imersa em relações de poder. Tal posicionamento parece ficar claro na seguinte fala:

[O inglês] está presente em muita coisa que é feita, produzida, divulgada, disseminada etc., e acho que conhecer ele, conhecer a língua ou, né, ter acesso aos recursos da língua pra poder entender te dá acesso a uma gama maior de discussões, de possibilidades, de opções. Então, acho que ele funciona nesse sentido, mas isso não é neutro, não é isento de poder, não deixa de segregar pessoas ou excluir pessoas disso ou dar certo poder para pessoas e às vezes não, também [...]. (Anderson)

Segundo o docente, ao mesmo tempo em que essa língua é hegemônica e dominante no mundo globalizado - permitindo, por meio dela, acesso a certos bens -, ela também pode excluir e marginalizar seres e conhecimentos diferentes.

Outro aspecto que nos chamou atenção foi a forma como uma das professoras afirma selecionar materiais para a sala de aula. Segundo Aline, quando o livro didático adotado pela instituição não é suficiente para determinado propósito, ela costuma levar mais exercícios gramaticais, conforme o trecho a seguir:

Trago [exercício] extra de gramática [...]. [...] tem aquele do Murphy64, [...] ou os exercícios que têm no livro do professor, do $A E F^{65}$, geralmente é de material assim. Além dos de gramática, eu faço os [exercícios] de vocabulário também [...]. Eu sempre procuro outros livros que têm teacher pack, teacher resources. (Aline)

\footnotetext{
${ }^{64}$ As gramáticas de Raymond Murphy, publicadas pela editora Cambridge, são materiais bastante conhecidos mundialmente e que contemplam diferentes fases e propósitos relacionados ao aprendizado da língua inglesa. Esses livros centram-se, basicamente, em explicações gramaticais e exercícios mecânicos sobre os temas apresentados.

${ }^{65}$ A professora refere-se à coleção American English File (AEF), da editora Oxford. Atualmente, o Celin adota o livro American English File - Starter para os níveis Básico 1 e 2. Entretanto, outros materiais da coleção já foram utilizados nos cursos da instituição.
} 
Nota-se que, para além de demonstrar uma preocupação forte com relação à estrutura da língua - a qual fica evidente no trecho antes referido -, Aline cita apenas materiais publicados por grandes editoras do norte global. Entendemos a facilidade e as vantagens dos materiais produzidos por esses centros hegemônicos, já que professores, frequentemente, convivem com condições precárias de trabalho, limitações de tempo, bem como exigências institucionais a respeito da escolha do livro didático. Contudo, ressaltamos a importância de um uso crítico e questionador desses materiais, já que muitos deles estão distantes da realidade local e, por vezes, propagam crenças e pensamentos que reforçam a linha abissal. No uso acrítico desses materiais, portanto, corremos o risco de nos tornarmos simples consumidores do que é produzido nesses espaços de poder, ao invés de produtores ativos do nosso próprio conhecimento.

Com relação aos outros três professores entrevistados, todos eles declararam ter uma relação mais independente com relação aos livros didáticos, utilizando-se, por exemplo, de materiais criados por eles mesmos a partir de demandas e observações locais. Sob nosso ponto de vista, tal posicionamento mostra indícios de desobediência epistêmica, que será discutida na seção seguinte.

\subsection{Traços desobedientes na perspectiva translíngue de ILF}

Como discutido em tópicos anteriores, entendemos desobediência epistêmica como o questionamento de padrões hegemônicos, a fim de promover a copresença e coexistência de diversas epistemologias. Ao pensarmos na nossa área de atuação, isto é, no ensino da língua inglesa, reconhecemos o quanto as contribuições da perspectiva translíngue de ILF nos parecem indicar um caminho direcionado à desobediência de uma lógica estabelecida e naturalizada, a qual está intimamente relacionada a imposições ocidentais/coloniais. Dessa forma, quando falantes da língua inglesa negociam sentidos a partir de seus valores, interesses e repertórios linguísticos, eles estão desafiando práticas e pensamentos 
considerados universais e transformando as realidades, ainda que apenas nos seus espaços específicos.

Nesse sentido, ao operarmos nas fissuras dos discursos hegemônicos referentes à língua inglesa, permitimos que as percepções, conhecimentos e necessidades daqueles que tradicionalmente são/foram silenciados e marginalizados sejam finalmente consideradas. Em outras palavras, no momento em que o falante de inglês demonstra agentividade e incentiva construções coletivas de conhecimento, sem sobrepor umas a outras, ele está trazendo justiça epistêmica, a qual, de acordo com Sousa Santos (2007), não está separada da justiça social global.

Destacaremos, por meio de trechos retirados das entrevistas, indícios de uma perspectiva translíngue de ILF nas falas dos professores. Com isso, reconhecemos, no discurso de alguns dos docentes, um possível caminho rumo a uma prática mais decolonial.

Um dos fatores que nos chamou a atenção e nos fez associar ILF e práticas translíngues com os caminhos decoloniais foi a forte preocupação de três dentre quatro professores com uma construção de práticas orientadas para os contextos específicos, visando alinhar-se aos anseios e realidades locais. Assim, quase todos comentaram a respeito da urgência de escutar os desejos dos alunos, bem como de conhecer os sujeitos que estão ali e o contexto que eles ocupam. Com o intuito de tornar o ensino/aprendizado mais coeso, muitos dos professores questionam imposições institucionais, principalmente aquelas referentes ao uso do livro didático. Nesse sentido, quando os docentes foram questionados acerca da relação com o material adotado pelo Celin, três dos quatro afirmaram transformá-lo de acordo com o interesse dos temas apresentados no livro, sempre tendo em conta os discentes.

Sobre isso, Giovana afirma que uma coisa que puseram na minha cabeça é [que] [...] vocês não são escravos do livro, o livro é escravo de vocês, então eu faço com ele o que eu quero. Seguindo a mesma linha de raciocínio, José afirma que se eu acho chato [um conteúdo do livro didático], eu pulo e tento trazer alguma coisa diferente, [...] algo que faça mais sentido para a vida dos alunos. 
Vemos aqui um exemplo da resistência, pois, apesar de o livro didático ser um produto vindo do norte global, o qual, em decorrência da colonialidade, adquire um status de superioridade e poder simbólico (BORDIEU, 1991) sobre o trabalho dos professores, os docentes ainda agem nas possíveis brechas (DUBOC, 2012), demonstrando controle e agência sobre seu uso.

Além da preocupação com o ensino situado, outra característica da perspectiva translíngue de ILF está na não separação entre as línguas, considerando que a competência comunicativa do falante está em sua habilidade de lançar mão de todos os seus recursos semióticos. Com relação a tal aspecto, três falas dos professores nos chamaram atenção. Primeiro, Giovana afirma: [o] que que meus alunos vão fazer? Falar. E falar em que língua? Inglês, porque foi assim que eu aprendi. Eu dificilmente falo com meus alunos em português. Por sua vez, José comenta: [e] u comecei com a crença de que a aula deveria ser toda em inglês, por conta das professoras que eu tinha observado anteriormente, mas eu fui mudando de perspectiva... principalmente fora de sala de aula. Por fim, temos a fala de Aline:

Eu digo [que] é inglês brasileiro [...]. [...] às vezes eu uso as nossas mesmas, as nossas idioms, [...] e eu tento traduzir elas pro inglês e pronto assim, sabe. E se alguém que só fala inglês não entende, aí eu tento explicar o que que significa, mas eu sempre tento trazer as coisas do Brasil, também, pro inglês. (Aline)

No caso do posicionamento da Giovana, podemos observar uma total separação entre o inglês e o português, e a crença no fato de que a aprendizagem deve acontecer dessa forma. Essa crença parece estar atrelada ao processo de aprendizagem da própria professora: foi assim que eu aprendi. A presença da língua materna como uma influência negativa no aprendizado é característica de uma perspectiva normativa de ILE, que, como afirmam Jordão e Marques (2018, p. 56), acaba “[...] estabelecendo padrões binários de certo e errado, correto e incorreto, possível e impossível” (tradução nossa ${ }^{66}$ ), os quais hierarquizam os usos da língua.

66 "[...] establishing binary patterns of right and wrong, correct and incorrect, possible and impossible". 
Por outro lado, José assume que iniciou seu trabalho com essa mesma crença, mas que suas vivências influenciaram uma transformação, principalmente fora de sala de aula. Observando, no questionário de perfil socioeducacional, que esse professor está em processo de graduação, acreditamos que suas experiências acadêmicas fazem parte das vivências por ele citadas, o que reforça a importância de processos de formação inicial/continuada.

Por fim, a fala de Aline parece demonstrar a tentativa de permitir a presença dos recursos provenientes da língua que reconhecemos como português nos seus usos em sala de aula. Como apontam García e Wei (2014, p. 42), na prática translíngue, falantes “[...] selecionam recursos de construção de sentidos e os combinam livremente com o intuito de potencializar a construção de sentido, o engajamento cognitivo, a criatividade e a criticidade" (tradução nossa ${ }^{67}$ ).

Outro aspecto da perspectiva de ILF neste trabalho é o do empoderamento dos falantes e do papel cada vez menos central do modelo do falante nativo, pois o dono da língua se torna qualquer falante, com seu próprio repertório (relembrando que as relações de poder não deixam de existir). Esse posicionamento parece estar presente na fala de José:

Gosto de acreditar que é [...] uma questão de alteridade, conhecer outra língua, outras realidades, outras culturas através do aprendizado de uma língua. [...] eu acredito que é isso, é deixar de ensinar um inglês que antes era a língua do outro e tentar ensinar um inglês que seja mais significativo pra esse aluno. (José)

Ele afirma que, antes, o inglês era a língua do outro, o que se alinha ao projeto moderno e colonial de um sistema que pertence a uma nação, a um território, mas que isso deixa de ser significativo para o aluno. Aline e Anderson também fizeram afirmações sobre suas visões de ILF:

[...] penso muito sobre... inglês como uma língua, uma língua franca né, que, tipo, você não necessariamente precisa saber tudo o que... gramatical ou de pronúncia pra você se fazer entender e entender o outro [...]. Mas assim, sempre pensando na ideia de que isso tá, é, questão de contexto, né. (Aline)

${ }_{67 "[\ldots]}$ [..] select meaning-making features and freely combine them to potentialize meaning-making, cognitive engagement, creativity and criticality". 
[...] eu pesquiso o papel do inglês hoje como língua franca, então é impossível que ele não afete as minhas práticas de sala de aula. Então, eu trago muita coisa do que eu tenho pesquisado, do que eu tenho visto que outras pessoas têm feito, né, pra tentar se aproximar dessa forma, aspas, de ensinar o ILF, que a ideia não é ter um modelo, não é ter uma forma única nem nada disso, mas ir adaptando a prática conforme o local onde você tá dando aula. (Anderson)

De certa forma, esses exemplos confirmam nossa expectativa, apresentada na metodologia deste trabalho, de que o contexto da pesquisa ser uma extensão da universidade possibilita que os professores tenham acesso às perspectivas mais recentes da LA. Aline demonstra que o conceito de ILF permeia suas reflexões e não é estranho a ela. Por sua vez, Anderson afirma que não só pesquisa sobre tal assunto, como também busca associar a teoria à prática. A partir das nossas interpretações a respeito do que foi dito nas entrevistas, acreditamos que ambos os professores associem ILF à ideia de que a comunicação, a inteligibilidade e a localidade têm mais relevância que normas pré-estabelecidas. Assim, conforme assinala Aline, o importante é [...] se fazer entender e entender o outro. Já Anderson aponta que, em ILF, a ideia não é [...] ter um modelo, não é ter uma forma única nem nada disso, mas ir adaptando a prática conforme o local onde você tá dando aula.

É interessante relembrar a forma fluida pela qual os professores se relacionam com a língua inglesa, pois, como mencionamos anteriormente, fazemos parte da colonialidade. Esse conflito no qual professores se situam pode ser observado, por exemplo, na fala de Anderson:

[...] é complicado dosar até que ponto a gente consegue realmente inserir essas coisas [perspectivas de ILF] na nossa prática, até que ponto o material didático, o sistema de avaliação, o local onde você trabalha te dá esse tipo de suporte pra poder ir fazendo essas mudanças, mas acho que elas vão vindo aos poucos, muito na forma como a gente trabalha certos assuntos, ou conduz as aulas, ou lida com a fala/escrita/produção dos alunos. (Anderson)

Outro exemplo desse conflito está na fala de Aline, quando ela afirma que [a]ntes de pensar numa atividade de speaking, eu preciso saber se eles vão ter condições de produzir aquilo. Daí eu sempre fico muito na dúvida, será que eu tenho que fazer um monte de exercícios de gramática? 
Observamos que Anderson reconhece inúmeras adversidades contextuais que podem dificultar ao professor a adoção de um pensamento ILF ou translíngue, elementos que são construídos ou concebidos a partir de uma perspectiva moderna/colonial de ILE e que têm forte poder simbólico, ou seja, muitas vezes servem de parâmetro e guia para as práticas dos professores. Entretanto, esse professor também enxerga um espaço de agência, uma possível brecha (DUBOC, 2012) para as mudanças. Em nosso entendimento, no ensino de ILF, o importante é alterar “[...] conceitos-base (língua, erro, competência etc.) que regem nossas práticas e, principalmente, trazer para os alunos a conscientização sobre o papel da língua inglesa, a natureza híbrida das formas linguísticas e a realidade fluida das interações comunicativas” (HAUS, 2019, p. 68). Além disso, como Anderson coloca, as mudanças estão vindo aos poucos, na forma como o professor conduz as aulas e lida com a produção dos alunos.

No caso da fala de Aline, notamos uma discrepância desse trecho com seu discurso sobre o conceito de ILF citado anteriormente. Primeiro, ela minimiza a importância da gramática ao falar de ILF. Posteriormente, com relação a como planeja suas atividades, ressalta a necessidade do foco na estrutura, sendo que esse trecho é apenas um exemplo das diversas vezes que a professora citou, na entrevista, o papel da gramática em suas aulas. Nas práticas translíngues, a estrutura não deve deixar de ser ensinada, mas dado que a gramática é gerada na prática e não pré-existente a ela, a negociação se torna o foco, se torna primária ao sentido.

Por meio dos discursos dos professores, notamos que, em determinados momentos e em diferentes graus, para uns e para outros, há um aparente movimento de reflexão e reestruturação das próprias práticas docentes ao incluir diversas vozes, deslocar o falante nativo do centro de sua prática, bem como questionar imposições vindas de contextos bastante distantes daqueles nos quais tais docentes atuam. Entretanto, ainda há um caminho de desconstruções e reflexões a percorrer, afinal, todos nós somos fruto da colonialidade e, por isso, fomos programados pelo pensamento europeu/colonial. É necessário desaprender aquilo que nos é colocado como natural, em um constante esforço 
decolonial (ANDREOTTI et al., 2015), a fim de garantir justiça social e justiça cognitiva global (SOUSA SANTOS, 2010).

Vale reforçar que nem todas as atitudes que aparentam um empoderamento dos falantes de inglês ou desconstrução da própria ideia de língua têm uma preocupação com a justiça social e diminuição do abismo social existente entre aqueles que estão deste e daquele lado da linha abissal. Preocupanos, por exemplo, a cooptação pelo neoliberalismo das ideias propagadas pela perspectiva de ILF, pois, no capitalismo neoliberal, as desigualdades são preservadas com o intuito de se manter a estrutura social, a qual, por sua vez, é sustentada pela exploração, hierarquização e exclusão de seres e saberes. Como consequência, promove-se a transformação e o empoderamento para poucos falantes de inglês, enquanto outros permanecem à margem, sem voz e sem possibilidades de ter contato com tais discussões. Portanto, para que promovamos a ecologia dentro do ensino e aprendizado da língua inglesa, é necessário lutar, coletivamente, contra a lógica neoliberal.

\section{Considerações finais}

O reconhecimento da colonialidade que permeia os diversos processos de globalização, de construção de conhecimento, de dominação e, principalmente para nós, de ensino e de aprendizagem de inglês leva-nos a buscar caminhos e opções decoloniais. Pesquisas que vêm sendo desenvolvidas na LA parecem se posicionar em uma tentativa de observar os fenômenos que envolvem a língua inglesa de forma menos opressora e hierárquica, bem como mais realista e adequada aos nossos objetivos comunicativos atuais, como é o caso da visão de ILF e práticas translíngues (apesar de reconhecermos que não são perspectivas totalmente desprendidas da colonialidade). Neste artigo, portanto, buscamos olhar para discursos de professores de inglês a respeito de suas práticas, a fim de observar elementos que indicassem uma perpetuação do pensamento colonial ou uma possível desobediência epistêmica. 
Por meio de nossas leituras das falas dos participantes, pudemos observar que, como sujeitos inseridos na colonialidade, os professores muitas vezes estão reproduzindo valores que mantêm perspectivas normativas e relações de poder assimétricas. Por isso, lembramos aqui a importância, conforme aponta Palhares (2011, p. 12), de nos questionarmos: “[...] que valores linguístico-culturais estão sendo transmitidos no processo de ensino-aprendizagem e como estes têm ajudado a manter as relações de poder e de desigualdade e a reproduzir o 'status quo'?”. Por outro lado, os participantes de nossa pesquisa também demonstram estar lançando mão de sua agência, muitas vezes agindo através de brechas (DUBOC, 2012), em direção a posicionamentos mais decoloniais. Assim sendo, gostaríamos de reformular a pergunta de Palhares (2011) e destacar a importância de pesquisas que investiguem esses valores linguístico-culturais que estão sendo transmitidos através do seguinte questionamento: como estes têm ajudado a manter e/ou questionar as relações de poder e de desigualdade e a reproduzir e/ou resistir o status quo?

Além disso, reforçamos o quanto um contexto acadêmico e rico em oportunidades, como é o caso do Celin - UFPR, precisa usufruir de seus espaços para manter um trabalho de formação inicial e continuada. Considerando o quanto a colonialidade permeia nosso ser e tudo aquilo que nos rodeia, conscientizar sobre o que é ILF, prática translíngue ou decolonialidade não é suficiente para modificar salas de aula de maneira efetiva e considerável. É necessário unir teoria e prática, promover uma formação que apresente conceitos relevantes relacionados com práticas concretas e situadas, reconhecendo os cotidianos e realidades em que esses sujeitos estão inseridos. Em suma, é necessário que haja um engajamento crítico, a fim de que efetivamente sejam reconstruídas práticas menos violentas e opressoras e mais adequadas a cada contexto histórico-social de atuação. 


\section{Referências}

ANDREOTTI, Vanessa; STEIN, Sharon; AHENAKEW, Cash; HUNT, Dallas. Mapping interpretations of decolonization in the context of higher education. Decolonization: Indigeneity, Education \& Society, v. 4, n. 1, p. 21-40, 2015. Disponível em: http://representing-education.gertrude cotter.info/wpcontent/uploads/2016/08/andreotti-stein-ahenakew-hunt-decolonization.pdf. Acesso em: 20 jul. 2019.

BORDIEU, Pierre. Language and symbolic power. Cambridge: Polity Press, 1991.

CANAGARAJAH, Suresh. Lingua Franca: English, Multilingual Communities, and Language Acquisition. The Modern Language Journal, v. 91, n. s1, p. 923939, 2007.

CANAGARAJAH, Suresh. Translingual Practice: Global Englishes and Cosmopolitan Relations. NY: Routledge, 2013.

DINIZ DE FIGUEIREDO, Eduardo Henrique; MARTINEZ, Juliana. The Locus of Enunciation as a Way to Confront Epistemological Racism and Decolonize Scholarly Knowledge. Applied Linguistics, v. Adv A, p. 1-6, 2019.

DUBOC, Ana Paula M. Atitude Curricular: Letramentos Críticos nas Brechas da Formação de Professores de Inglês. 258 f. Tese (Doutorado em Letras) Universidade de São Paulo, São Paulo, 2012.

FRIEDRICH, Patricia. MATSUDA, Aya. When Five Words Are not Enough: A Conceptual and Terminological Discussion of English as a Lingua Franca. International Multilingual Research Journal, v.4, n. 1, p.20-30, 2010.

GARCÍA, Ofélia. WEI, Li. The Translanguaging Turn and Its Impact. In: GARCÍA, Ofélia. WEI, Li. Translanguaging: Language, Bilingualism and Education. Basingstoke: Palgrave Macmillan, p. 19-44, 2014.

GROSFOGUEL, Ramón. Racismo/sexismo epistémico, universidades occidentalizadas y los cuatro genocídios/epistemicidios del largo siglo XVI. Tabula Rasa, Bogotá, n. 19, p. 31-58, jul-dez, 2013.

HAUS, Camila. Inglês como Língua Franca e prática translíngue: uma perspectiva possível. Versalete, v. 7, n. 12, p. 51-71, 2019.

JENKINS, Jennifer. Repositioning English and multilingualism in English as a Lingua Franca. Englishes in Practice, v. 2, n. 3, p. 49-85, 2015. 
JORDÃO, Clarissa Menezes. A língua inglesa como commodity: Direito ou obrigação de todos? Conhecimento local e conhecimento universal, v.3, n. 1, p. 272-295, 2004.

JORDÃO, Clarissa Menezes. A posição de professor de inglês no Brasil:

hibridismo, identidade e agência. Letras \& Letras, v. 26, n. 2, 21 mar. 2010.

JORDÃO, Clarissa Menezes; MARQUES, Anderson Nalevaiko. English as a lingua franca and critical literacy in teacher education: Shaking off some "good old” habits. In: GIMENEZ, Telma; KADRI, Michele Salles El; CALVO, Luciana Cabrini Simões. English as a Lingua Franca in Teacher Education - A Brazilian perspective. 1ed, De Gruyter Mouton, p. 53-68, 2018.

KUMARAVADIVELU, Bala. Dangerous liasion: Globalization, Empire and TESOL. In: EDGE, Julian. (Ed.). (Re)Locating TESOL in an age of empire. New York: Palgrave Macmillan, p. 1-26, 2009.

MAHER, Terezinha. Políticas linguísticas e políticas de identidade: currículo e representações de professores indígenas na Amazônia ocidental brasileira. Currículo sem Fronteiras, v. 10, n. 1, p. 33-48, jan./jun. 2010.

MAKONI, Sinfree; PENNYCOOK, Alastair. Disinventing and Reconstituting Languages. In: MAKONI, Sinfree; PENNYCOOK, Alastair (ed). Disinventing and Reconstituting Languages. Bristol: Multilingual Matters Ltd, p. 1-37, 2007.

MALDONALDO-TORRES, Nelson. Sobre la colonialidad del sur: contribuiciones al desarollo de un concepto. In CASTRO-GOMÉZ, Santiago, GROSFOGUEL, Ramón. El giro decolonial: reflexiones para una diversidad epistémica más alla del capitalismo global (compiladores). Bogotá: siglo del Hombre Editores, Universidad Central, Instituto de Ciencias Sociales Comtemporaneos y Pontificia Universidad Javeriana, Instituto Pensar, p. 127168, 2007.

MALDONALDO-TORRES, Nelson. A topologia do Ser e a geopolítica do conhecimento. Modernidade, império e colonialidade. Revista Crítica de Ciências Sociais, 80, Março 2008.

MENEZES DE SOUZA, Lynn Mario T. Glocal Languages, coloniality and globalization from below. In: GUILHERME, Manuela; MENEZES DE SOUZA, Lynn Mario T. Glocal Languages and Critical Intercultural Awareness - The South answers back. 1ed. NY: Routledge, p. 17-41, 2019.

MIGNOLO, Walter. Desobediência epistêmica: a opção decolonial e o significado de identidades em política. Cadernos de Letras da UFF. Dossiê Literatura, língua e identidade, n. 34, p. 287-324, 2008.

MIGNOLO, Walter. Educación y decolonialidad: aprender a desaprender para 
poder re-aprender - Um diálogo geopolítico-pedagógico com Walter Mignolo. Revista del IICE. n. 35, p. 61-71, 2014. [Entrevista concedida a Facundo Giuliano e Daniel Berisso].

MOITA LOPES, Luiz Paulo da. Uma Linguística Aplicada mestiça e ideológica. In: MOITA LOPES, Luiz Paulo da (Org.). Por uma Linguística Aplicada indisciplinar. São Paulo: Parábola Editorial, p. 13-44, 2006.

MUFWENE, Salikoko. Globalization, Global English, and World English(es): Myths and Facts. In: COUPLAND, Nikolas. (ed). Handbook of Language and Globalization. New Jersey: Wiley-Blackwell, p. 31-55, 2010

NORTON, Bonny. Critical literacy and international development. Critical literacy: Theories and Practices, v. 1, n. 1, p. 6-15, 2007.

PALHARES, Ana Cristina de Moraes Hazin. Língua, cultura, educação e colonialidade: Reflexões sobre o ensino-aprendizagem de línguas em uma perspectiva pós-colonial. Interfaces de Saberes, v. 12, n. 1, 2011.

PENNYCOOK, Alastair. English and the discourses of colonialism, Londres: Routledge, 1998.

PENNYCOOK, Alastair. Translingual English. Australian review of applied linguistics, v. 31, n. 3, p. 30.1-30.9, 2008.

QUIJANO, Anibal. Coloniality of Power, Eurocentrism, and Latin America. Nepantla: Views from South, v. 1, n. 3, 2000.

SIQUEIRA, Sávio. Inglês como Língua Franca não é zona neutra, é zona transcultural de poder: Por uma descolonização de concepções, práticas e atitudes. Línguas e Letras, v. 19, n. 44, p. 93-112, 2018.

SOUSA SANTOS, Boaventura. Beyond abyssal thinking: from global lines to ecologies of knowledge. Review (Fernand Braudel Center), v. 30, n. 1, p. 45-89, 2007.

SOUSA SANTOS, Boaventura. Para além do pensamento abissal: das linhas globais a uma ecologia dos saberes. In: SOUSA SANTOS, Boaventura, MENESES, Maria Paula. (Orgs.) Epistemologias do Sul. São Paulo: Cortez, p. 31-83, 2010.

SOUSA SANTOS, Boaventura. A Universidade do Século XXI: para uma reforma democrática e emancipatória da Universidade. 3ed. São Paulo: Cortez, 2011. 
Artigo recebido em 20 de maio de 2020 e aceito em 6 de agosto de 2020. 